\title{
Hydrolysis of Hydroxamic Acid Complexants in the Presence of Non-Oxidizing Metal Ions
}

Scott Edwards ${ }^{1}$, Fabrice Andrieux ${ }^{1}$, Colin Boxall ${ }^{1}$, Robin Taylor ${ }^{2}$, David Woodhead ${ }^{2}$

${ }^{1}$ Engineering Deparment, Lancaster University, Lancaster, Lancashire, LA1 4YW, U.K.

${ }^{2}$ The National Nuclear Laboratory, Central Laboratory, Sellafield, Cumbria, CA20 1PG, U.K.

\section{ABSTRACT}

Simple Hydroxamic acids (XHAs) are salt free, organic compounds with affinities for hard cations such as $\mathrm{Fe}^{3+}, \mathrm{Np}^{4+}, \mathrm{Pu}^{4+}$ and have been identified as suitable reagents for the control of $\mathrm{Pu}$ and $\mathrm{Np}$ in advanced nuclear fuel reprocessing. Building upon previous work on the neptunium(IV)-formohydroxamic(FHA) acid system [1], a model that describes the hydrolysis of the acetohydroxamate moiety has been extended to include hydrolysis of bishydroxamatoneptunium(IV) complex. The model has been used to determine the rate constants for hydrolysis of mono- and bis-acetohydroxamatoneptunium(IV) at $25^{\circ} \mathrm{C}$, which were found to be $1.0 \times 10^{-5} \mathrm{dm}^{3} \mathrm{~mol}^{-1} \mathrm{~s}^{-1}$ and $5.0 \times 10^{-5} \mathrm{dm}^{3} \mathrm{~mol}^{-1} \mathrm{~s}^{-1}$, respectively.

\section{INTRODUCTION}

All commercial nuclear fuel reprocessing plants currently use the hydrometallurgical plutonium Uranium Extraction (PUREX) process to separate uranium and plutonium from used nuclear fuel. This process results in the isolation of plutonium from the reprocessing liquor, posing proliferation issues. Additionally, neptunium an actinide decay product that is not currently recycled as fuel, is found in a number of PUREX process streams including the separated $\mathrm{U}$ and $\mathrm{Pu}$ streams and the highly active waste stream. The former raises questions of process efficiency while the latter raises disposal issues. Several adaptations to PUREX have been suggested, one such adaptation is Advanced PUREX (or UREX+), which uses simple hydroxamic acids (XHAs) to coextract plutonium and neptunium from the reprocessing liquor leaving uranium unaffected [2], thereby addressing the main issues of PUREX.

Such XHAs are known to be useful due to their ability to complex hard cations such as $\mathrm{Fe}^{3+}, \mathrm{Np}^{4+}$ and $\mathrm{Pu}^{4+}$ as well as their ability to reduce metal ions; for example, they rapidly reduce $\mathrm{Np}(\mathrm{VI})$ to $\mathrm{Np}(\mathrm{V})$ [3]. These properties may allow for redox control of $\mathrm{Np}$ and $\mathrm{Pu}$ in the U/Pu separation column and remove the need for organic salts, which can create disposal problems further downstream. However, hydroxamic acids undergo hydrolysis in acidic media, which could have negative implications in advanced nuclear fuel reprocessing.

Hydrolysis of hydroxamates in acidic solutions is known to take place on the free ligand and when bound to a metal centre, although only the former is well characterized [4]. This paper seeks to better understand the kinetics of hydrolysis of the metal bound ligand, ultimately leading to the design of meaningful Advanced PUREX flowsheets.

Previous modeling work focused on hydrolysis of the monohydroxamatoneptunium(IV) complex using a semi analytical model [1]. Extension of the previous model to conditions where the bishydroxamatoneptunium(IV) complex is also present is non-trivial. The present work uses a numerical modeling approach to determine rates of hydrolysis of the mono and bis complexes. 
In addition, acidity and ionic strength effects have been taken into account, beyond the scope of the earlier semi analytical model.

\section{EXPERIMENTAL}

$\mathrm{Np}(\mathrm{IV})$ aqueous stock solutions were prepared as described previously [5]. Gram quantities of $\mathrm{NpO}_{2}$ were dissolved by refluxing in strong $\mathrm{HNO}_{3}$ until virtually complete dissolution was obtained. The resulting $\mathrm{Np}(\mathrm{VI})$ solution was reduced with substantial excess of $\mathrm{Fe}(\mathrm{II})\left(\mathrm{FeCl}_{2}\right)$. The $\mathrm{Np}$ (IV) solution was purified from $\mathrm{Fe}$ and $\mathrm{Cl}$ ions by solvent extraction into $30 \%$ tributyl phosphate (TBP) in odourless kerosene and backwashing into $\mathrm{HNO}_{3}$. The acid concentration would then be adjusted by addition of $\mathrm{HNO}_{3}$ and the solution sampled for $\mathrm{Np}$ analysis. All other reagents including $\mathrm{HNO}_{3}(70 \%$, AnalaR, BDH Chemicals Ltd., Poole, Dorest, UK) and AHA (Sigma-Aldrich Ltd UK) were obtained from reputable suppliers at the highest available purity and used as received.

AHA was stored at $4{ }^{\circ} \mathrm{C}$ in order to prevent decomposition; solutions were prepared immediately prior to experiments in order to prevent hydrolysis, by room temperature dissolution of an accurately weighed portion into distilled water.

UV-visible, near-infra-red (near IR) electronic absorption spectra (EAS) were recorded using a Perkin Elmer Lambda 19 spectrophotometer coupled by fibre optics to an external sample compartment for remote safe analysis of the $\alpha$-active radioisotope ${ }^{237} \mathrm{~Np}$. Solutions for the kinetic experiments of $\mathrm{Np}(\mathrm{IV})$-AHA complex stability were prepared by mixing aliquots of $\mathrm{Np}(\mathrm{IV})$ stock, $\mathrm{HNO}_{3}$ and $\mathrm{AHA}$ directly into an optical cuvette of pathlength $1 \mathrm{~cm}$; the complexant was added last. During the kinetic absorbance measurements the spectrometer was set to scan the range 350-1000 $\mathrm{nm}$ at variable time intervals. All spectra were corrected to account for baseline shifts between experiments [1].

gPROMS (General PROcess Modelling System) an advanced custom modeling software (Process Systems Enterprise, UK) was used to model the hydrolysis of free and Np bound hydroxamate. Rate constants for the hydrolysis of the mono- and bis-hydroxamatoneptunium(IV) complexes were fitted using the gPROMS parameter estimation function.

\section{DISCUSSION}

Previous work has shown that the Np(IV)-AHA system forms complexes with AHA:metal ratios from 1:1 to 3:1 (equations 1-3). Equilibrium constants $\left(\mathrm{K}_{1}-\mathrm{K}_{3}\right)$ for these $\mathrm{Np}$ (IV)-AHA complexes have been obtained in non-complexing perchlorate media at constant ionic strength [5]. However, given that most hydrometallurgical fuel separations and recycling processes utilize an aqueous phase containing concentrated $\mathrm{HNO}_{3}$, formation of neptunium(IV) mono- and di-nitrate (equations 4-5) complexes must be taken into account as they limit the availability of $\mathrm{Np}$ (IV) able complex with the hydroxamate. In this context, SIT coefficients for formation constants of $\mathrm{Pu}(\mathrm{IV})$ mono- and di-nitrate [6] complexes have been found to be good proxies for modeling $\mathrm{Np}(\mathrm{IV})$ nitrate complexation behavior and thermodynamics [7]; unfortunately, such relationships do not exist for the hydroxamato complexes. Further, $\mathrm{HNO}_{3}$ partially dissociates in solutions of high ionic strength (equation 6) and this must be taken into consideration due to the effect on proton and nitrate concentration on ligand hydrolysis and cation complexation. Protonation of AHA (equation 7) occurs in highly acidic media and is known to have a rate limiting effect on hydrolysis of the hydroxamate complex [8]. Furthermore, 
protonation of the mono and bis complex may occur, having a similar affect to that of the free AHA [9]. These reactions are summarized in equations 1 to 7 below $25^{\circ} \mathrm{C}$ and I $=1.0 \mathrm{~mol} \mathrm{~kg}^{-1}$

$$
\begin{aligned}
& H L+N p^{4+} \stackrel{K_{1}}{\rightleftarrows} N p L^{3+}+H^{+} \quad \mathrm{K}_{1}=2750 \\
& \mathrm{HL}+\mathrm{NpL}^{3+} \stackrel{\mathrm{K}_{2}}{\rightleftarrows} \mathrm{NpL}_{2}^{2+}+\mathrm{H}^{+} \quad \mathrm{K}_{2}=5.49 \\
& \mathrm{HL}+\mathrm{NpL}_{2}^{2+} \stackrel{K_{3}}{\rightleftarrows} \mathrm{NpL}_{3}^{+}+\mathrm{H}^{+} \quad \mathrm{K}_{3}=4.47 \times 10^{-2} \\
& \mathrm{~Np}^{4+}+\mathrm{NO}_{3}^{-} \stackrel{\beta}{\rightleftarrows} \mathrm{NpNO}_{3}^{3+} \quad \beta_{1}=2.3=\alpha \cdot 10^{\left(\log \beta_{1}^{0}-\Delta \varepsilon_{1} I-8 \mathrm{D}\right)} \\
& \mathrm{Np}^{4+}+2 \mathrm{NO}_{3}^{-} \stackrel{\beta_{2}}{\rightleftarrows} \mathrm{Np}\left(\mathrm{NO}_{3}\right)_{2}^{2+} \quad \quad \beta_{2}=4.1=\alpha^{2} \cdot 10^{\left(\log \beta_{2}{ }^{0}-\Delta \varepsilon_{2} I-14 \mathrm{D}\right)} \\
& \mathrm{HNO}_{3} \stackrel{\mathrm{K}_{A_{\mathrm{HNO} \mathrm{O}_{3}}}}{\rightleftarrows} \mathrm{H}^{+}+\mathrm{NO}_{3}^{-} \quad \mathrm{pK}_{A_{H N O_{3}}}=-1.41 \\
& H L+H^{+} \stackrel{K_{A_{1}}}{\rightleftarrows} H L H^{+} \quad \quad \mathrm{K}_{\mathrm{A}_{1}}=3 \text { (estimated value [9]) }
\end{aligned}
$$

where $\mathrm{HL}$ is $\mathrm{AHA} ; \mathrm{L}$ is the hydroxamate (HA) ligand; $\beta_{1}$ and $\beta_{2}$ are the formation constants of the mono- and di-nitrate complex; $\beta_{1}{ }^{0}$ and $\beta_{2}{ }^{0}$ are the formation constants of monoand di-nitrate complex at infinite dilution; $\alpha$ is the degree association of $\mathrm{HNO}_{3}$; $\mathrm{D}$ is the DebyeHuckel term; $\Delta \varepsilon_{1}$ and $\Delta \varepsilon_{2}$ are the ion interaction correction coefficients; I is the ionic strength measured in molality; $\mathrm{HLH}^{+}$is the protonated AHA molecule.

Equations 8 to 10 show the hydrolysis reactions that occur in solution, producing acetic acid and hydroxylamine, kinetic rate equations for these processes being given by equations 1113 , respectively.

$$
\begin{aligned}
& \mathrm{HL}+\mathrm{H}^{+} \stackrel{\mathrm{k}_{0}}{\longrightarrow} \mathrm{CH}_{3} \mathrm{COOH}+\mathrm{NH}_{3} \mathrm{OH}^{+} \\
& \mathrm{NpL}^{3+}+2 \mathrm{H}^{+} \stackrel{\mathrm{k}_{1}}{\longrightarrow} \mathrm{Np}^{4+}+\mathrm{CH}_{3} \mathrm{COOH}+\mathrm{NH}_{3} \mathrm{OH}^{+} \\
& \mathrm{NpL}_{2}^{2+}+2 \mathrm{H}^{+} \stackrel{\mathrm{k}_{2}}{\longrightarrow} \mathrm{NpL}^{3+}+\mathrm{CH}_{3} \mathrm{COOH}+\mathrm{NH}_{3} \mathrm{OH}^{+} \\
& \frac{d[\mathrm{HL}]}{d t}=\mathrm{k}_{0}[\mathrm{HL}]\left[\mathrm{H}^{+}\right] \\
& \frac{d\left[\mathrm{NpL^{-5 }}{ }^{3+}\right]}{d t}=\mathrm{dm}_{1}\left[\mathrm{NpL}^{-1} \mathrm{~s}^{3+}\right]\left[\mathrm{H}^{+}\right] \\
& \frac{d\left[\mathrm{NpL_{2 }}{ }^{2+}\right]}{d t}=\mathrm{k}_{2}\left[\mathrm{NpL}_{2}{ }^{2+}\right]\left[\mathrm{H}^{+}\right]
\end{aligned}
$$

The purpose of this work is to determine values of $\mathrm{k}_{1}$ and $\mathrm{k}_{2}$ from experimental kinetic hydrolysis data in the context of the reaction scheme given by equations 9 and 10 .

Kinetic hydrolysis experiments were conducted on the Np(IV)-AHA system as a function of $\left[\mathrm{HNO}_{3}\right]$ at fixed $[\mathrm{AHA}]$ and as a function of $[\mathrm{AHA}]$ at fixed $\left[\mathrm{HNO}_{3}\right]$. Extent of hydrolysis was monitored by following the absorbance of the $1: 1$ and 2:1 complexes at $732 \mathrm{~nm}$, figures $1 \mathrm{a}-1 \mathrm{f}$. 

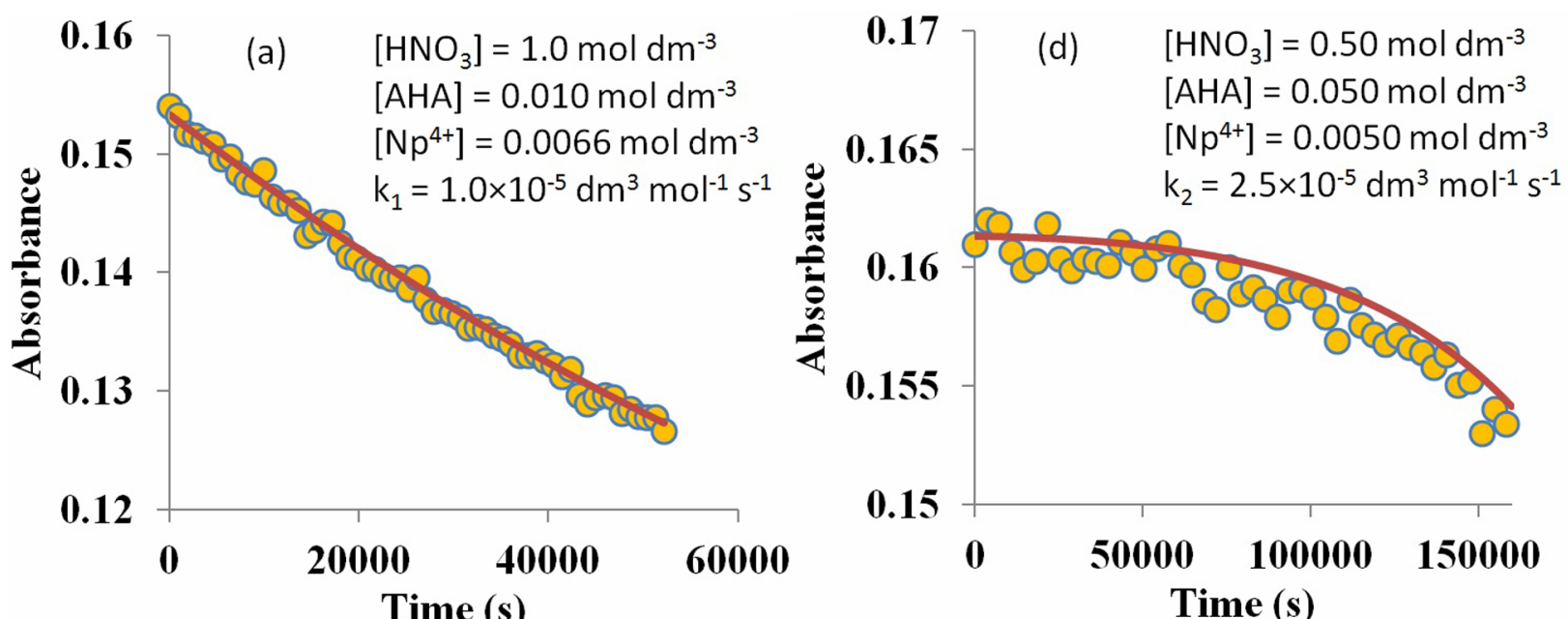

Time (s)
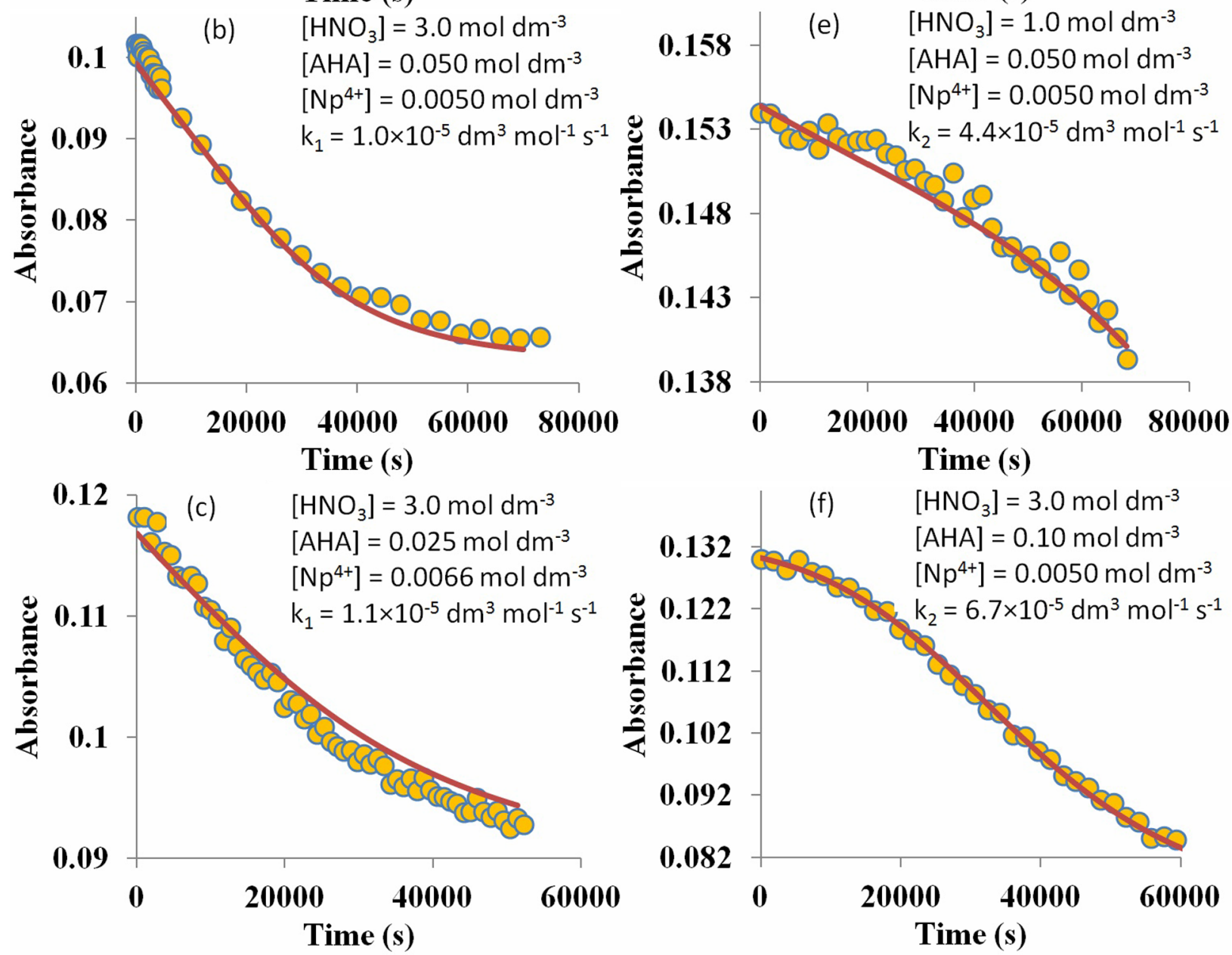

Figure 1. Plots of experimental $(\mathrm{O})$ and modelled (_ $)$ absorbance of the $\mathrm{Np}(\mathrm{IV})$-AHA system at $732 \mathrm{~nm}$, under conditions where the solution contains $\mathrm{NpL}^{3+}$ only (a-c) and under conditions where the solution contains $\mathrm{NpL}^{3+}$ and $\mathrm{NpL}_{2}{ }^{2+}$ (d-f). $\mathrm{NpL}^{3+}$ and $\mathrm{NpL}_{2}{ }^{2+}$ extinction coefficients used are $32 \mathrm{dm}^{3} \mathrm{~mol}^{-1}$ and $38 \mathrm{dm}^{3} \mathrm{~mol}^{-1}$, respectively. 
Rate constants were determined for these data using the parameter estimation facility of the custom process modeling software, gPROMS. This facility uses a maximum likelihood formulation to determine constants and performs statistical analysis on the results [10]. Simulated rate constants for the hydrolysis of the mono complex are given in table I.

Table I. Experimental conditions and fitted rate constants for $\mathrm{k}_{1}$ hydrolysis of the monohydroxamatoneptunium(IV) complex at $25^{\circ} \mathrm{C}$

\begin{tabular}{ccccccc}
\hline Experiment & $\begin{array}{c}{\left[\mathrm{HNO}_{3}\right] /} \\
\mathrm{mol} \mathrm{dm}^{-3}\end{array}$ & $\begin{array}{c}{\left[\mathrm{Np}^{4+}\right] /} \\
\mathrm{mol} \mathrm{dm}^{-3}\end{array}$ & $\begin{array}{c}{[\mathrm{AHA}]_{0} /} \\
\mathrm{mol} \mathrm{dm}^{-3}\end{array}$ & $\begin{array}{c}\text { Percentage } \\
\text { of }\left[\mathrm{Np}^{4+}\right] \text { as } \\
{\left[\mathrm{NpL}_{2}^{2+}\right]_{0} / \%}\end{array}$ & $\begin{array}{c}\text { Fitted } \mathrm{k}_{1} / \\
\mathrm{dm}^{3} \mathrm{~mol}^{-1} \\
\mathrm{~s}^{-1}\end{array}$ & $\begin{array}{c}95 \% \text { Confidence } \\
\text { Interval/ } \mathrm{dm}^{3} \\
\mathrm{~mol}^{-1} \mathrm{~s}^{-1}\end{array}$ \\
\hline 1 & 3.0 & 0.0050 & 0.050 & 5.4 & $1.0 \times 10^{-5}$ & $3.0 \times 10^{-6}$ \\
10 & 3.0 & 0.0066 & 0.025 & 0.51 & $1.1 \times 10^{-5}$ & $3.3 \times 10^{-6}$ \\
13 & 1.0 & 0.0066 & 0.010 & 1.9 & $1.0 \times 10^{-5}$ & $4.0 \times 10^{-6}$ \\
\hline
\end{tabular}

The rate constants values of Table I were determined under conditions where the concentration of the bis complex is not significant in comparison to the concentration of the mono complex, allowing for more accurate evaluation of the latter within the fitting procedure. Values of rate constants for hydrolysis of the mono complex are in good agreement, the mean value being $1.0 \times 10^{-5} \mathrm{dm}^{3} \mathrm{~mol}^{-1} \mathrm{~s}^{-1}$, which is the same as that determined for the $\mathrm{Np}$ (IV)-FHA system [1]. There is no evidence of ionic strength and acidity effects on the rate constant $\mathrm{k}_{1}$ when $\left[\mathrm{HNO}_{3}\right] \leq 3 \mathrm{~mol} \mathrm{dm}^{-3}$. Additionally, equation 11 can be seen to be a linear approximation of the dependence of the concentration of the hydrolysis entity $\mathrm{HLH}^{+}$on $\left[\mathrm{H}^{+}\right]$. This dependence is more accurately described by the equilibrium of equation 7 , suggesting that at high $\left[\mathrm{H}^{+}\right]$the concentration of $\left[\mathrm{HLH}^{+}\right]$will saturate i.e. the linearity of equation 8 will be lost. The consistency of $\mathrm{k}_{1}$ values suggests a lack of any $\left(\mathrm{HLH}^{+}\right)$saturation effects on the acidity range studied.

Table II. Experimental conditions and fitted rate constant $\mathrm{k}_{2}$ for the hydrolysis of the bishydroxamatoneptunium(IV) complex at $25^{\circ} \mathrm{C}$

\begin{tabular}{ccccccc}
\hline Experiment & $\begin{array}{c}{\left[\mathrm{HNO}_{3}\right] /} \\
\mathrm{mol} \mathrm{dm}^{-3}\end{array}$ & $\begin{array}{c}{\left[\mathrm{Np}^{4+}\right] /} \\
\mathrm{mol} \mathrm{dm}^{-3}\end{array}$ & $\begin{array}{c}{[\mathrm{AHA}]_{0} /} \\
\mathrm{mol} \mathrm{dm}^{-3}\end{array}$ & $\begin{array}{c}\text { Percentage } \\
\text { of }\left[\mathrm{Np}^{4+}\right] \text { as } \\
{\left[\mathrm{NpL}_{2}^{2+}\right]_{0} / \%}\end{array}$ & $\begin{array}{c}\text { Fitted k } \\
\mathrm{dm}^{3} \mathrm{~mol}^{-1} \\
\mathrm{~s}^{-1}\end{array}$ & $\begin{array}{c}95 \% \text { Confidence } \\
\text { Interval } / \mathrm{dm}^{3} \\
\mathrm{~mol}^{-1} \mathrm{~s}^{-1}\end{array}$ \\
\hline 4 & 3.0 & 0.0050 & 0.10 & 12 & $6.7 \times 10^{-5}$ & $3.2 \times 10^{-5}$ \\
6 & 1.0 & 0.0050 & 0.050 & 19 & $4.4 \times 10^{-5}$ & $2.1 \times 10^{-5}$ \\
9 & 0.50 & 0.0050 & 0.050 & 32 & $4.0 \times 10^{-5}$ & $2.5 \times 10^{-5}$ \\
\hline
\end{tabular}

Fitted rate constants for hydrolysis of the bis complex are given in Table II with $\mathrm{k}_{2}$ being found to have a mean value of $5.0 \times 10^{-5} \mathrm{dm}^{3} \mathrm{~mol}^{-1}$. The value of $\mathrm{k}_{1}$ is less than that for the hydrolysis of the free ligand $\mathrm{k}_{0}$ due to the positive charge of the complex, leading to the hydrolysis-preceding protonation step becoming less likely to occur. The value of $\mathrm{k}_{2}$ is more than $\mathrm{k}_{1}$ due to the charge of the bis complex being less than the mono complex, hence the protonation step occurs more easily. Furthermore, there are two protonation sites on the $\mathrm{NpL}_{2}{ }^{2+}$ complex making hydrolysis more likely to occur.

Individual values of $\mathrm{k}_{2}$ in Table II are not in as good agreement with each other as those for the mono complex with the $\mathrm{k}_{2}$ value obtained from Experiment Reference Number 4 being 50 $\%$ higher than the value obtained from Experiments 6 and 9. Interestingly, Experiment 4 has a considerably higher initial concentration of AHA than that used in experiments 6 and 9, 
suggesting that the apparent higher value of $\mathrm{k}_{2}$ obtained may be due to: (i) reduction of $\mathrm{Np}$ (IV) to $\mathrm{Np}$ (III) driven by accumulation of hydroxylamine as a result of excess AHA hydrolysis; or (ii) presence of a mixed $\mathrm{Np}: \mathrm{NO}_{3}$ :AHA complex. We expect that latter to be true as there is no evidence from UV-vis spectrophotometry to suggest presence of $\mathrm{Np}$ (III). The mixed $\mathrm{Np}(\mathrm{IV}): \mathrm{NO}_{3}$ :AHA complex will lead to a decrease in the positive charge of the complex, thus easier protonation than in the $\mathrm{Np}(\mathrm{IV})$-AHA complex and a greater rate of hydrolysis .

\section{CONCLUSIONS}

For the first time, a value for the hydrolysis of the bishydroxamatoneptunium(IV) complex has been determined at $25^{\circ} \mathrm{C}$ to be $5.0 \times 10^{-5} \mathrm{dm}^{3} \mathrm{~mol}^{-1} \mathrm{~s}^{-1}$. A value for the hydrolysis of the monohydroxamatoneptunium(IV) at $25^{\circ} \mathrm{C}$ has been determined to be $1.0 \times 10^{-5} \mathrm{dm}^{3} \mathrm{~mol}^{-1} \mathrm{~s}^{-1}$, which is the same as that determined for the $\mathrm{Np}$ (IV)-FHA system [1]. Relative values of these rates parameters and their size with respect to $\mathrm{k}_{0}$, have been interpreted in terms of coulomb repulsion. The rate constant $\mathrm{k}_{2}$ is found to be largest at the highest concentration of AHA used in these experiments. This would suggest the presence of another complex which is most likely 1:1:1 Np(IV): $\mathrm{NO}_{3}: \mathrm{AHA}$.

\section{ACKNOWLEDGMENTS}

The authors wish to thank the Engineering and Physical Science Research Council UK for provision of an EngD award to support SAE, The National Nuclear Nuclear Laboratory and The Lloyds Register Educational Trust for additional financial support. The Lloyds Register Educational Trust is an independent charity working to achieve success in transportation, science, engineering and technology, education, training and research worldwide for the benefit of all.

\section{REFERENCES}

1. F. Andrieux, C. Boxall, I. May, and R. Taylor, Journal of Solution Chemistry 37, 215 (2008).

2. E. Birkett, M. Carrott, D. Fox, C. Jones, C. Maher, C. Roube, R. Taylor, and D. Woodhead, CHIMIA International Journal for Chemistry 898 (2005).

3. B. Colston, G.R. Choppin, and R.J. Taylor, Radiochimica Acta 88, 329 (2000).

4. DY Chung, J Lee, Ind Eng Chem 12, 962 (2006).

5. R.J. Taylor, S.I. Sinkov, G.R. Choppin, and I. May, Solvent Extraction and Ion Exchange 26, 41 (2007).

6. J. Berg, D. Veirs, R. Vaughn, M. Cisneros, and C. Smith, Journal of Radioanalytical and Nuclear Chemistry 235, 25 (1998).

7. M.J. Sarsfield, H.E. Sims, and R.J. Taylor, Solvent Extraction and Ion Exchange 29, 49 (2011).

8. A. Buglass, M. Dorr, and M. Juffkins, Tetrahedron Letters 28, 3283 (1987).

9. F.P.L. Andrieux, C. Boxall, and R.J. Taylor, Journal of Solution Chemistry 36, 1207 (2007).

10. Available: http://www.psenterprise.com/gproms/technologies/model_validation.html. [Accessed: 13-Nov-2011]. 